\title{
TŁUMACZ: UWAŻNY CZYTELNIK I POŚREDNIK. LITERATURA BUŁGARSKA W NAJNOWSZYCH PRZEKŁADACH WOJCIECHA GAŁĄZKI
}

\author{
Sylwia Siedlecka \\ University of Warsaw
}

\begin{abstract}
THE TRANSLATOR: A CAREFUL READER AND INTERMEDIARY. BULGARIAN LITERATURE IN THE LATEST TRANSLATIONS BY WOJCIECH GAŁAZZKA. The aim of the article is to discuss the latest translation initiatives by Wojciech Gałązka, a Bulgarian and literary scholar from Krakow, and a prominent translator of Bulgarian prose and poetry. Over the course of several months, between 2019 and 2020, seven works by Bulgarian writers and poets translated by Wojciech Gałązka were published: the novel Under the Yoke by Ivan Vazov (2020); the books of poetry: Revealed from Anywhere by Petar Parvanov (2019), Seasons of Feelings by Petar Karaangov (2020), Moon Spots by Nikolay Liliev (2020), A Dream of Happiness by Pencho Slaveykov (2020), as well as poetic prose and poems included in the collection Against the Absence by Nikolay Kantchev (2020). The review of Gałązka's translation initiatives included in the article has been supplemented with a commentary on specific problems related to both translation practices (sound and grammatical structures, translatability of idiomatic expressions, taking into account a literary convention in the process of translation) and broader issues related to the understanding of translation as a transfer between cultures (the requirement of mastering the contexts and traditions of both cultures that the translation concerns) and the understanding of the role of the translator himself, whom Gałązka describes as a careful reader and intermediary between cultures.
\end{abstract}

Keywords: Wojciech Galazka, translation, Bulgarian literature, poetry, Polish literature, cultural transfer

Książka miała twardą granatową oprawę, jej treść była wydrukowana czcionką używaną w ręcznych maszynach do pisania. Tytuł: Naród i kultura, rok wydania: 1985, skrypt uczelniany numer 508 Uniwersytetu Jagiellońskiego (Galazka 1985). Znajdowała się na liście naszych lektur z literatury bułgarskiej, które na warszawskiej slawistyce prowadziła profesor (wówczas doktor) Grażyna Szwat-Gyłybowa. Dla studentek i studentów bułgarystyki, nieczytających jeszcze w oryginale, ten wybór z literatury bułgarskiej był ważnym źródłem wiedzy o kulturze, którą zaczynaliśmy wtedy poznawać. Ten otwierający szeroką perspektywę zbiór stanowił świetny punkt wyjścia do dyskusji na zajęciach, własnych przemyśleń, a także skłaniał do tego, by w dialogiczny sposób potraktować tworzące go eseje i artykuły 
- ich układ i zawartość wręcz zachęcały do podjęcia takiego działania. Książka zawierała fragmenty dzieł kluczowych dla bułgarskiej literatury, od końca XVIII wieku (Paisija Chilendarskiego), przez XIX wiek i autorów odrodzenia narodowego, po pierwsze dekady $\mathrm{XX}$ wieku, kiedy intensywne przemiany polityczne i modernizacyjne skłaniały bułgarskich literaturoznawców, poetów i pisarzy do projektów, mających na celu wydestylowanie tego upragnionego produktu finalnego, zwanego charakterem narodowym.

Po paru latach oryginał książki gdzieś zaginął, pewnie jeden ze studentów, który opuścił instytut nie rozliczył się z biblioteką. Kolejne roczniki były więc skazane na kopie, które przy każdym kolejnym powielaniu zacierały obraz oryginału maszynopisu. Na kopii pojawiały się nowe, wprowadzane przez kolejne roczniki studentów, uwagi na marginesach, podkreślenia, wykrzykniki, znaki zapytania. Sama wielokrotnie próbowałam kupić oryginał, ale znalezienie go w antykwariatach internetowych graniczyło z cudem. Zadając studentom lektury z tej książki, korzystam do dziś z kopii, opatrzonej zresztą dedykacją, umożliwiającą też zrekonstruowanie oryginału tego konkretnego egzemplarza: Pani Profesor Teresie Dąbek-Wirgowej z podziękowaniami za recenzję i z serdecznościami - Wojciech Gałązka, Kraków 12.02.1986.

Zbiór Naród i kultura był moim pierwszym kontaktem z literackimi inicjatywami Wojciecha Gałązki. Do dziś zresztą uważam, że ten starannie skomponowany, syntetyczny wybór rozmawiających ze sobą tekstów był i pozostaje książką ważną, którą można by w dzisiejszych kategoriach określić jako szczególnego rodzaju non-fiction, czyli teksty będące dokumentami określonego miejsca w czasie, które czytać można właśnie w taki sposób: jako zapis autowyobrażeń, mitów, cyklicznie ponawianych prób nazywania, reinterpretacji i rozumienia zmieniającej się rzeczywistości. A poza tym wszystkim widzę tę książkę jako ważny gest bezinteresowności wobec studentów, zwłaszcza pierwszych lat bułgarystyki, którzy dzięki książkom jak ta mogli dostać, wtedy jeszcze w czasie ograniczonej dostępności baz elektronicznych, szerszą perspektywę spojrzenia na wiele kluczowych kwestii kulturowo-literackich, a nade wszystko - rozniecić w sobie ciekawość wobec bułgarskiej kultury.

Na kolejnych latach studiów poznałam prace literaturoznawcze Wojciecha Gałązki: Tradycja i współczesność. O literaturze bułgarskiej XX wieku (1983), Bułgarskie programy i manifesty literackie (1983); przekłady, jak ten w antologii Spis powszechny dzikich zajęcy (1975), Biała jaskółka. Antologia opowiadań bułgarskich XIX i XX wieku (1982) oraz Niewidzialne skrzydła. Antologia poezji bułgarskiej od IX wieku do 1944 roku (1987), przekład powieści Antychryst Emiliana Stanewa (1979), tłumaczenia poezji Atanasa Dałczewa i Nikołaja Kynczewa. Literaturoznawstwo Wojciecha Gałązki miało to do siebie, że wytrącało mnie ze schematów myślowych, pozwalało inaczej spojrzeć na sprawy pozornie znane. 
Miałam i nadal mam wrażenie, że autor dzieli się ze mną efektami przemyśleń, które stanowią wynik uważnego i wielostronnego, osadzonego w rozległych kulturowych kontekstach spojrzenia na bułgarską literaturę. A lektura esejów Gałązki, czyli gatunków pogranicznych, meandrujących, pozwalających zboczyć ze ścieżek naukowego dyskursu, dawała mi dodatkową satysfakcję, ponieważ obok intelektualnej zawartości wywody eseistyczne Gałązki krystalizowały się w gęste od znaczeń metafory, jak choćby tę kluczową, upostaciowioną w skorpionie, wyrażającym obcość kulturową, którą oswoić można między innymi poprzez literaturę i przekład (Galazka 1992).

Celem niniejszej pracy nie jest jednak wspominanie, lecz omówienie najnowszych inicjatyw przekładowych Wojciecha Gałązki, bowiem w ciągu zaledwie 2 lat, między 2019 a 2020 rokiem w przekładzie tego wybitnego bułgarysty, literaturoznawcy i tłumacza ukazało się aż siedem przekładów utworów bułgarskich pisarzy i poetów: począwszy od powieści Iwana Wazowa Pod jarzmem (Vazov 2020), przez tomy poetyckie: Petyra Karaangowa Sezony uczuć (Karaangov 2020), Petyra Pyrwanowa Skądkolwiek wyjawiony (Parvanov 2019), Nikołaja Liliewa Odblaski księżyca (Liliev 2020), Pencza Sławejkowa Sen o szczęściu (Slaveykov 2020) oraz Nikołaja Kynczewa Przeciwko nieobecności (Kantchev 2020) - ten ostatni zawierający oprócz wierszy prozę poetycką. Polscy czytelnicy otrzymali w niedługim czasie efekt wieloletniej pracy Wojciecha Gałązki; efekt, na który składają się przekłady dzieł autorów należących do ścisłego kanonu literatury bułgarskiej (Wazow, Sławejkow, Liliew, Kynczew), jak również znanych dotąd polskiemu czytelnikowi incydentalnie (Pyrwanow), a niekiedy dotychczas nieobecnych w polskich przekładach (Karaangow).

Głównymi źródłami naświetlającymi kwestie omawiane w kolejnych podrozdziałach, są wypowiedzi samego Wojciecha Gałązki, czyli artykuły naukowe, wywiady i posłowia do książek, zogniskowane wokół tematyki przekładowej. Kluczowym źródłem wykorzystanym w pracy jest obszerna rozmowa przeprowadzona z Wojciechem Gałązką na potrzeby tego artykułu przez jego autorkę w pierwszej połowie 2020 roku (wywiad ukaże się drukiem w 2021 roku).

\section{POD JARZMEM: PRZEKEAD JAKO REINTERPRETACJA UTWORU}

Opublikowany w 2020 roku przekład Pod jarzmem Iwana Wazowa w tłumaczeniu Wojciecha Gałązki jest trzecim przekładem na język polski tej fundamentalnej dla bułgarskiej literatury powieści, wydanej po raz pierwszy w 1894 roku. Dwutomowe, starannie wydane i wzbogacone ilustracjami wydanie pierwsze w przekładzie Heleny Sopodźkowej ukazało się po polsku zaledwie pięć lat po wydaniu oryginału bułgarskiego, natomiast drugie wydanie w tłumaczeniu Teresy Waniek z 1950 roku doczekało się w Polsce trzech wznowień w ciągu zaledwie dekady. W rozmowie z Mitko Nowkowem, zamieszczonej w bułgarskim piśmie 
Kultura, Wojciech Gałązka stwierdził, że poprzednie przekłady na język polski sprawiły, że długo odkładał lekturę powieści w oryginale. Jednak powtórzona po latach lektura Wazowa w języku bułgarskim odsłoniła przed autorem przekładu potencjał, tkwiący między innymi w rozmachu stylistycznym i w metaforyzacji świata przedstawionego (Novkov 2020). Jak pisze Gałązka w komentarzu Od tłumacza, zamykającym trzeci przekład powieści, utwór Wazowa w równym stopniu opowiada (jako narracyjno-fabularna warstwa z kluczowym wątkiem przygodowym), co mówi. W tym drugim sensie jest utworem wchodzącym w dia$\log$ z literaturą, między innymi poprzez liczne przywołania literackie, konteksty, dialog z konwencjami, konstruowanie bohaterów, gry językowe, imiona i przydomki mówiq̨ce, zabiegi narracyjno-retoryczne, orkiestracje brzmieniowe w opisach i w opowieści narracyjne, jak również zabiegi w kreowaniu świata przedstawionego, w którym ważną rolę odgrywa humor, karnawałowość oraz wielojęzyczność bohaterów (Galazka 2020: 490).

O pracy nad przekładem powieści Wazowa Wojciech Gałązka napisał obszerne studium, które ukazało się w czwartym numerze Zeszytów Cyrylo-Metodiańskich (Galazka 2015: 5-48). Ten opublikowany w 2015 roku (pięć lat przed ukazaniem się przekładu powieści w formie książkowej) artykuł wskazuje rozmach przedsięwzięcia tłumacza, pokazując przekład jako efekt i rezultat długich badań, które doprowadziły Gałązkę do reinterpretacji i odkrycia nowych pokładów sensu tego dzieła literackiego. Podobne, czyli poprzedzone rozległymi badaniami nad dziełem, podejście towarzyszyło pracy Gałązki również wcześniej, w trakcie pracy nad innymi przekładami: powieści Antychryst Emiliana Stanewa, spolszczonej w konwencji legendy i noweli Indże Jordana Jowkowa napisanej po polsku w konwencji ballady. Jak stwierdza tłumacz: Proza bułgarska wykazuje duża skłonność do uwznioślania tematów, bohaterów poprzez takq oprawę gatunkowo-stylistyczną. Te utwory dają więcej możliwości przekładania z kultury do kultury. Bez mała cała proza Jordana Jowkowa jest „ukrytą” transpozycją wielu wątków biblijnych, łącznie z przestrzenia regionu Dobrudży jako ziemskiego, dobrego raju. Pokłady metaforyczności w prozie bułgarskiej, choć nie zawsze oczywiste, sq bardzo rozległe. A sami Bułgarzy mówiq o własnej literaturze, że jest nazbyt realistyczna (wywiad w druku).

Zjawisko metaforyzacji w bułgarskiej literaturze, zdaniem Wojciecha Gałązki niewystarczająco uwzględnione w bułgarskiej krytyce literackiej, powinno być w opinii autora przekładu Pod jarzmem uwzględnione w możliwie najwyższym stopniu, również w procesie przekładu: Tłumacz nie może tu nic zmienić w sposób istotny. Może tylko ewentualnie bardziej uwydatnić, o ile owo uwydatnienie jest uzasadnione jego rodzima kultura, do której przekłada dany utwór. Bo tak przecież bywa, że pewien rys kulturowy może funkcjonować w jego własnej kulturze w sposób wyrazistszy, choć z punktu widzenia funkcjonalności jeden i drugi sq sobie równoważne, ale inna jest ich intensywność w odbiorze (wywiad w druku). 
Na pytanie o emblematyczny utwór, który można by zaproponować polskiemu czytelnikowi, nie znającemu bułgarskiej literatury, a chcącemu ją bliżej poznać, Wojciech Gałązka odpowiedział mi, że byłaby to właśnie powieść Wazowa Pod jarzmem. Zdaniem autora przekładu utwór ten, choć powstał pod koniec XIX wieku, jest dziełem uniwersalnym, dającym się czytać na wielu poziomach i zawierającym w sobie przesłanie skierowane także do dzisiejszego odbiorcy. Można nawet próbować umocować tę powieść w kontekście filozofii polskiej historii i czytać ją jako utwór o miejscu i roli historii w życiu narodu: Wolność człowieka i niepodległość narodu sq u Wazowa dziejowq koniecznością, ale walka o nie, niepoparta racjonalnq strategia i właściwa oceną sytuacji, jest natchnionym szaleństwem, jak mówi wprost sam Wazow. Utwór zaczyna się w scenerii i atmosferze wręcz karnawałowej, a kończy wyłącznie tragicznie. W kategoriach racjonalnych jest to niemądre szaleństwo, ale w sferze emocjonalnej zasługuje na poetyckie uwznioślenie, jako próba realizacji marzenia o istnieniu w historii. Skojarzenia z polskimi powstaniami staja się nieuchronne, także $w$ sferze ich ocen i interpretacji. Niezależnie od tego jak bardzo donioste jest to przesłanie, to problem wolności ma w „Pod jarzmem” wymiar znacznie szerszy. Dotyczy również wyzwolenia się z ograniczeń narzuconych przez obyczajowość patriarchalna, a nawet zaskakująco aktualnie brzmiących postulatów praw kobiet, których rodowód (socjalistyczny) sięga końca XIX wieku (wywiad w druku).

\section{BIEGUNY MODERNISTYCZNEJ WYOBRAŹNI: PENCZO SŁAWEJKOW I NIKOŁAJ LILIEW}

W 2020 roku w wydawnictwie Scriptum (w cyklu Mała Biblioteka Literatury Bułgarskiej) ukazały się dwa tomy poetyckie w przekładzie Wojciecha Gałązki: Sen o szczęściu Pencza Sławejkowa (zawierający cykl miniatur Sen o szczęściu / Сън за щастие z 1906 roku i wybór z Księgi pieśni / Книга на песните z 1917 roku) oraz zbiór wierszy Nikołaja Liliewa Odblaski księżyca / Лунни петна z 1922 roku. Polscy czytelnicy otrzymali tym samym obszerny wybór z twórczości wybitnych modernistów, reprezentujących dwa bieguny modernistycznej wyobraźni: należącego do pierwszej fali modernizmu Sławejkowa oraz uosabiającego kulminację modernistycznej wyobraźni Liliewa.

Księga pieśni, czyli zebrany i kompozycyjnie opracowany przez Sławejkowa zbiór bułgarskich pieśni ludowych (polski tom stanowi ich wybór), jest zdaniem Wojciecha Gałązki dziełem, w którym na tyle głęboko odcisnęła się ingerencja samego Sławejkowa, że można Księgę potraktować jako zbiór autorski: (...) Sławejkow wyjmuje z tekstów oryginalnych pewne ich fragmenty, tworzy strofy, wprowadza tu i ówdzie rymy. Jednym słowem tworzy bardzo często nowe utwory. Cały układ kompozycyjny zaś, zorganizowany tematycznie, tworzy wizję świata w pieśni ludowej, której świat jest jakby upostaciowiona na kształt ludzki 
całością. Ma ludzkq̨ duszę. W moim wyborze utwory z „Księgi pieśni” jedynie to sygnalizują, gdyż całość, ze względu na dużą objętość, wymaga odrębnej publikacji (wywiad w druku).

Pieśń ludowa istotna była nie tylko w obszernym zbiorze Księga pieśni Sławejkowa, ale stanowi niezwykle ważną artystyczną inspirację dla wielu innych twórców literackich. Myśląc o przekładzie polsko-bułgarskim, warto wziąć pod uwagę sam status pieśni ludowych w obu kulturach. Podczas gdy w wymiarze wykonawczym bułgarskie pieśni mają charakter rytualny, związany z określonym kontekstem rytualnym, związek polskich pieśni ludowych z rytuałem jest dużo bardziej rozluźniony. Jeśli zaś chodzi o transfery ludowości do poezji, bułgarska literatura zasilana jest strumieniem twórczości ludowej od połowy XIX wieku aż do współczesności, co widać w twórczości Christo Botewa, Iwana Wazowa, Pencza Sławejkowa, Peja Jaworowa, Kiriła Christowa, Asena Razcwetnikowa, Elizawety Bagriany, a współcześnie choćby Płamena Dojnowa. Szczególnie rozległe są te transfery właśnie w pierwszej fazie moderny. Sprowadzają się do różnego rodzaju stylizacji, ale i do swoistego oglądu, w którym podmioty świata przedstawionego sq wpisywane w mit, a składniki przedmiotowe w rezultacie personifikacji petniq role społeczne. Tradycja pieśni ludowej uobecnia się w poezji także niezliczoną ilościa mott, za którymi nie idzie stylizacja. Są one natomiast swoista „intonacja” w warstwie metaforycznej poszczególnych utworów (wywiad w druku).

W przypadku przekładu modernistycznej poezji ważnym zagadnieniem staje się również szeroko rozumiana warstwa brzmieniowa, która stanowi odrębne, choć sprzężone z warstwą słowną wyzwanie translatorskie. Zdaniem Wojciecha Gałązki tłumacz ze względu na różnice foniczne między językami polskim i bułgarskim nie tyle powinien szukać zbliżenia brzmieniowego, co wychodząc od tego, że brzmieniowość odgrywa istotną rolę, określić stopień jej nasycenia i użyte środki jej uzyskania. Jako przykład Gałązka podaje słowo motyl w języku polskim i nenepyдa w języku bułgarskim, które: (...) mimo jednakowego znaczenia, wywołują w odbiorze na tyle odmienne asocjacje brzmieniowe, że w utworze poetyckim może to rzutować na różna aurę „dźwięczności” ich lotu. To nie znaczy rzecz jasna, że któraś z nich jest bardziej lub mniej pasująca do motyli, ona jest po prostu inna (wywiad w druku). Mechanizm przywoływania odmiennych asocjacji można odnaleźć w wierszu Liliewa z tomu Odblaski księżyca:

$\begin{array}{ll}\text { Светло утро, ти прокуди } & \text { Jasny ranku, trwałeś chwilę, } \\ \text { всяка пара и мъгла - } & \text { by mgły wznieść powiewem - } \\ \text { пеперуди, пеперуди, } & \text { i motyle, i motyle, } \\ \text { тънки сребърни крила. } & \text { srebrnych skrzydeł zewem. (Liliev 2020: 5) }\end{array}$

Wojciech Gałązka komentuje ten fragment następująco: Można odnieść wrażenie, że istota motyla w języku butgarskim sq kruchość i delikatność, a w polskim - lekkość i zwiewność 
(zwłaszcza, że zastosowałem inny rodzaj rymów i stóp rytmicznych w wersie drugimi czwartym). Cechq wspólnq w tej istotności jest nietrwałość jego bytu. Zgodna zreszta z prawdq obiektywną. Sam ich lot podczas jasnego i (jak można się domyślić) rześkiego poranka, tuż po akcie kreacji świata z mgiet, sugerowany jest występującymi naprzemiennie różnymi stopami rytmicznymi (wywiad w druku).

Istotnym czynnikiem, dotyczącym nie tylko poezji, ale w niej właśnie generującym wiele pytań i konieczności translatorskich rozstrzygnięć, jest uwzględnienie w przekładzie struktur gramatycznych języka bułgarskiego: Aby wyrazić zależności między podmiotem i dopetnieniem, wymagającymi często rodzajników postpozytywnych, które czy to w formie krótkiej, czy petnej sq jednosylabowe, niezbędne jest użycie przyimka, który też jest jednosylabowy. W poezji klasycznej, w której rytm, metrum i rym odgrywają istotna rolę, ta arytmetyka ma swoje konsekwencje dla wszystkich powyższych kategorii wersyfikacyjnych, ale też dla kształtu metafory. Bardzo trudno jest w niej zderzyć znaczeniowo dwa elementy przedmiotowe. Jako przykład bułgarysta podaje również Nikołaja Liliewa, który użył właśnie epitetu metaforycznego, tytułując zbiór Лунни петна. Zdaniem Gałązki epitet metaforyczny bliższy jest poezji bułgarskiej ze względu na strukturę języka bułgarskiego, a tłumacz tę strukturę powinien brać pod uwagę, kierując się racjonalnym uzasadnieniem, jakim w przypadku Liliewa było wpisanie poezji Bułgara w polską (w tym wypadku romantyczną) tradycję literacką: Ja odwróciłem w przekładzie strukturę gramatyczną tej metafory, ponieważ moim zdaniem jest ona bardziej nowoczesna, bliższa poezji współczesnej, jeśli jej granica początkowa miałaby być poezja awangardowa, ale przecież ten typ metafory występuje już w polskim romantyzmie, choćby u Słowackiego. W każdym razie epitet metaforyczny jest bliższy poezji bułgarskiej aż do czasu, kiedy odchodzi ona od klasycznych wzorców wersyfikacyjnych (wywiad w druku).

\section{PODPOWIERZCHNIOWE STANY NAPIĘCIA: PETYR PYRWANOW I PETYR KARAANGOW}

W odstępie kilku miesięcy w przekładzie Wojciecha Gałązki ukazały się w wydawnictwie Miniatura dwa tomy poetyckie: Sezony uczuć Petyra Karaangowa (2020) i obszerny dwujęzyczny tom poetycki Skądkolwiek wyjawiony Petyra Pyrwanowa (2019). Obu tych poetów łączą związki z polską kulturą. Petyr Karaangow (ur. 1931) należy do słynnego pokolenia kwietniowego, które nadało ton poezji bułgarskiej po tzw. odwilży 1956 roku. Karaangow pracował jako redaktor czasopism literackich i tłumacz literatury polskiej. Jego przekłady ukazały się zwłaszcza w antologii współczesnych poetów polskich z 1967 roku, która w Bułgarii stała się ważnym wydarzeniem literackim i odcisnęła ślad również w językach poetyckich niektórych bułgarskich twórców. 
Wojciech Gałązka przetłumaczył wiersze Karaangowa już pod koniec lat osiemdziesiątych. Wydany niedawno tom Sezony uczuć stanowi wybór z twórczości Karaangowa, poety właściwie osobnego, peryferyjnego również wobec generacji kwietniowców. W intymnej, wyciszonej liryce tego poety wyczuwa się inspirację rytmem pór roku i cyklów przyrody, można też dostrzec natchnienia z poezji Gałczyńskiego, którą Karaangow cenił.

Z kolei obszerny dwujęzyczny tom Petyra Pyrwanowa jest wyborem z całej twórczości tego poety, prywatnie pozostającego od wielu lat w przyjaźni z Wojciechem Gałązką (wspólnie przygotowali bułgarskie wydania poezji Leśmiana i Norwida). Twórczość Karaangowa i Pyrwanowa łączą stany napięcia, działającego jednak w sposób subtelny, podpowierzchniowy. Dramaturgia tych utworów jest ukryta, mają one wymiar kontemplacyjny, a jednocześnie cechuje je dynamika, ruch, ciągła przemiana, która wcale tej kontemplacji nie wyklucza, a - jak się zdaje - właśnie dzięki niej jest możliwa.

Petyr Pyrwanow jest twórcą trudnym w przekładzie - między innymi dlatego Gałązka zadecydował o dwujęzycznym przekładzie tych wierszy. Zawarty w tomie wybór z twórczości poety, określonej przez literaturoznawcę Swetłozara Igowa jako postklasyczna, jest utkany z erudycyjnych odniesień do greckiego antyku, kultury hebrajskiej i chińskiej. Trudność w przekładzie Pyrwanowa wynika zwłaszcza z nieużywania interpunkcji, co powoduje rozluźnienie logicznych sensów i to, że tłumacz - nie znajdując oparcia w gramatyce - sam musi podejmować wiele rozstrzygających decyzji, projektując niejako własną potencjalną interpunkcję. W odniesieniu do tej strategii projektowania interpunkcji Gałązka używa określenia bieg wsteczny, który, obecny w języku bułgarskim, jest prawie niemożliwy do zastosowania w języku polskim. Jako przykład polski tłumacz podaje dwa ostatnie wersy wiersza (bez tytułu), który można czytać na trzy sposoby, zależnie od decyzji tłumacza dotyczącej umiejscowienia znaków interpunkcyjnych:

1) Na biegu wstecznym

обратът към съдбата е отворил яснота в прозореца саждив и окислен, дъждът дълбок се рони неизбежно (zwrócenie się ku losowi przywiodło jasność do okna zakopconego i zmętniałego deszcz ulewny pada nieuchronnie) (Pyrwanow, 2019: 82)

2) Postawienie przecinka po słowie okno, które umożliwia odniesienie przymiotników rozpoczynających drugi wers zarówno do okna, jak i do deszczu:

обратът към съдбата е отворил яснота в прозореца, саждив и окислен, дъждът дълбок се рони неизбежно 
(Jak dodaje Gałązka, w przekładzie tego efektu już by nie było i fragment ten brzmiałby jak ciemny (osmolony?) i kwaśny, ulewny deszcz... Nie brzmi to teraz zręcznie, ale deszcz można by nazwać w wierszu mianem 'саждив', skoro i grzyba, zwanego po polsku 'gąskq niekształtna', nazywa się 'саждива гъба' - wywiad w druku).

3) Przymiotniki rozpoczynające wers drugi odnosić się mogą tylko do deszczu, a wówczas projektowana interpunkcja wygląda tak:

обратът към съдбата е отворил яснота в прозореца,

саждив и окислен - дъждът дълбок се рони неизбежно. (wywiad w druku)

\section{NIKOŁAJ KYNCZEW: POETA FRAZEOLOGICZNY}

O Nikołaju Kynczewie (1936-2007) należałoby wspomnieć już wcześniej, bowiem to dzięki niemu (pośrednio) polski czytelnik ma możliwość lektury nowego przekładu powieści Pod jarzmem. Wieloletnia fascynacja Kynczewa powieścią Wazowa stała się jedną z kluczowych przyczyn podjęcia ponownej lektury tego dzieła (tym razem w języku bułgarskim) przez Wojciecha Gałązkę. Tłumacz zresztą dedykuje przekład Kynczewowi, pisząc: Pamięci poety Nikołaja Kynczewa, który przybliżył mnie do ocen i ducha tej powieści.

Obszerny tom poezji i prozy poetyckiej Przeciwko nieobecności (2020) stanowi próbę zebrania dotychczasowych tłumaczeń Wojciecha Gałązki, obejmujących twórczość tego wybitnego poety. Gałązka, wieloletni przyjaciel Kynczewa, zebrał w nim wszystkie swoje dotychczasowe (powstające już od lat sześćdziesiątych) przekłady wierszy Kynczewa na polski, dodając nowe, powstałe w ostatnich latach życia poety. Tom z 2020 roku zawiera zbiór Niczym ziarno gorczycy wydany w 1981 roku w Wydawnictwie Literackim oraz wydany w 1999 roku w dwóch językach tom Posłanie od piechura.

Kynczew jest poetą trudnym do przekładu, jednak z innego względu niż przywołany wcześniej Pyrwanow. Poezja Kynczewa buduje sensy, wykorzystując związki frazeologiczne, a zatem takie, których łączliwość związana jest ściśle ze społecznym kontekstem i utrwalonym w społecznym użytkowaniu zwyczajem. Skoro, podążając za intencją Gałązki, zadaniem tłumacza miałoby być uwzględnienie w przekładzie kontekstu tradycji i kultury, do której przekład następuje, to w przypadku poezji frazeologicznej powstaje jeszcze jedno zadanie, mianowicie wydobycie frazeologizmu, który ma podobny semantyczny i społecznie nacechowany ciężar; a w razie potrzeby wypełnienie luki frazeologicznej w danym języku (co przecież też jest możliwe, bo jedna kultura nie musiała wypracować frazeologizmu, jaki ukształtowała inna). Zagęszczenie frazeologizmów u Kynczewa jest duże i zdarza się, że związki tego typu występują w niemal każdym wersie wiersza. W tym sensie wyzwaniem dla przekładu jest nie tylko znalezienie ekwiwalentu frazeologicznego, ale również takiej konfiguracji ekwiwalentów, które wspólnie zbudują spójną, przekonującą, ale i oddającą sens 
/ aurę oryginału konstelację frazeologiczną. Jak pisze Gałązka: W wierszach z ostatnich lat życia częstotliwość i zagęszczenie frazeologizmów sq̨ tak duże, że chyba nie da się ich przetłumaczyć na żaden język. I zapewne w każdym z języków braknie jednego lub kilku frazeologizmów. Czasami myślę sobie, i takie mam dogłębne wrażenie, że język w tej poezji mówi sam. Dużo w niej frazeologizmów, zagadek słownych, gry językowej, kalamburów, sentencji, paradoksu a więc tego wszystkiego, co organicznie jest w języku i poeta tylko uruchamia ten językowy arsenat do wyrażenia siebie i świata. To wcale nie jest łatwe (wywiad w druku).

Można zadać pytanie, jak z kolei stworzyć przekład, który mówi sam, zachowując jednocześnie łączność z oryginałem wiersza i ową organiczność w języku polskim. Na to pytanie potrafię odpowiedzieć jedynie posługując się przykładem, jak ten z wiersza Duch wodny:

W poezji nawet litera nie znaczy literalnie.

Jakie by nie było jej znaczenie, posłuży wszystkim.

Zamyślone. Powiedziane nie wprost. Ulotne.

Fala rzuca swoje kości: wygraną zgarnie morze. (Kantchev 2020: 10)

Wojciech Gałązka rozumie rolę tłumacza literatury jako uważnego czytelnika, a zarazem pośrednika między autorem a kulturą docelową (Novkov 2020). Pozycja tłumacza jako uważnego czytelnika wydaje się dziś często zaniechana w przekładzie, jako wymagająca znajomości reguł i zasad literatury (a zatem czasu i gromadzenia wiedzy), a następnie dostrzeżenia ich również w tłumaczonym dziele. Widzi ona przekład nie jako pierwsze i jedyne, a jedno z ogniw wieloetapowej pracy tłumacza - pierwszym etapem pozostaje owa uważna lektura, przygotowująca solidny grunt dla przekładu. Z kolei rola tłumacza-pośrednika wiąże się z przeniesieniem jednego języka w drugi, i jednej kultury w drugą, z uwzględnieniem całej nagromadzonej wiedzy zarówno o kulturze i języku oryginału, jak i przekładu.

W tym sensie praca tłumacza dotykałaby dwóch biegunów aktywności, każąc tłumaczowi-uważnemu czytelnikowi w mnisim skupieniu zgłębiać księgi, wychwytywać niuanse i mikrodrgnienia literatury. A z drugiej strony, tłumaczowi-pośrednikowi każąc działać w ruchu, migotliwości kulturowych odniesień, otwarciu na kulturowe styki, lustra i zazębienia, by moc zbudować pomosty między jedną kulturą a drugą: kulturą oryginału i przekładu. Można by pomyśleć, że w tej drugiej roli tłumacz jest kimś w rodzaju Hermesa, kursującego między światem bogów i ludzi, ale tak nie jest - towarzyszy mu przecież uważny czytelnik. 


\section{REFERENCES}

Galazka 1985: Galazka, Wojciech, ed. Nation and Culture : An Anthology of Essays and Articles on the Bulgarian Nation and Culture. University scripts no 508. Krakow: Jagiellonian University Press, Institute of Slavic Philology, 1985. [In Polish: Gałązka, Wojciech, ed. Naród i kultura. Antologia esejów i artykutów o narodzie i kulturze bułgarskiej. Skrypty uczelniane nr 508. Kraków: Uniwersytet Jagielloński, Instytut Filologii Słowiańskiej, 1985.]

Galazka 1992: Galazka, Wojciech. Taming Scorpions : Sketches on Bulgarian Literature. Krakow: Secesja, 1992. [In Polish: Gałązka, Wojciech. Oswajanie skorpionów. Szkice o literaturze butgarskiej. Kraków: Secesja, 1992.]

Galazka 2015: Galazka, Wojciech. "Translating Ivan Vazov's Under the Yoke." Zeszyty CyryloMetodianskie, no 4 (2015): 5-48. [In Polish: Gałązka, Wojciech. „Tłumacząc Pod jarzmem Iwana Wazowa." Zeszyty Cyrylo-Metodiańskie, no 4 (2015): 5-48.]

Galazka 2020: Galazka, Wojciech. "From the Translator." In: Vazov, Ivan. Under the Yoke: On the Life of Bulgarians on the Eve of the Liberation: 489-491. Transl. from Bulgarian by W. Galazka. Krakow: Scriptum, 2020. [In Polish: Gałązka, Wojciech. „Od tłumacza.” W: Wazow, Iwan. Pod jarzmem. Z życia Bułgarów w przededniu wyzwolenia: 489-491. Tłum. z bułgarskiego W. Gałązka. Kraków: Scriptum, 2020.]

Kantchev 2020: Kantchev, Nikolay. Against the Absence. Poems and Poetic Prose. Transl. by W. Galazka. Krakow: Scriptum, 2020. [In Polish: Kynczew, Nikołaj. Przeciwko nieobecności. Wiersze i proza poetycka. Kraków: Scriptum, 2020.]

Karaangov 2020: Karaangov, Petar. Seasons of Feelings. Poems. Transl. by W. Galazka. Krakow: Miniatura, 2020. [In Polish: Karaangow, Petyr. Sezony uczuć. Kraków: Miniatura, 2020.]

Liliev 2020: Liliev, Nikolay. Moon Spots. Poetry. Transl. by W. Galazka. Krakow: Scriptum, 2020. [In Polish: Liliew, Nikołaj. Odblaski księżyca. Kraków: Scriptum, 2020.]

Novkov 202o: Novkov, Mitko. "The Careful Mediator. A Conversation with Wojciech Galazka." Interview. Kultura (Sofia), no 7 (2970 / 2020): 12-14. [In Bulgarian: Новков, Митко. „Внимателният посредник. Разговор с Войчех Галонзка.” Интервю. Култура, nо 7 (2970 / 2020): 12-14.]

Parvanov 2019: Parvanov, Petar. Revealed from Anywhere. Poems. Transl. by W. Galazka. Krakow: Miniatura, 2019. [In Polish: Pyrwanow, Petyr. Skądkolwiek wyjawiony. Kraków: Miniatura, 2019.]

Slaveykov 2020: Slaveykov, Pencho. Dream of Happiness. Transl. by W. Galazka. Krakow: Scriptum, 2020. [In Polish: Sławejkow, Penczo. Sen o szczęściu. Kraków: Scriptum, 2020.]

Vazov 2020: Vazov, Ivan. Under the Yoke: On the Life of Bulgarians on the Eve of the Liberation. Transl. from Bulgarian by W. Galazka. Krakow: Scriptum, 2020. [In Polish: Wazow, Iwan. Pod jarzmem. Z życia Bułgarów w przededniu wyzwolenia. Tłum. z bułgarskiego W. Gałązka. Kraków: Scriptum, 2020.] 